( AlTL I L. R. B.. \& SC III II R. I. H. Handbook for the obisctive-analytic (O-A) anxict! hatters. (!)impalen. III: IP'Al. 1960.

I PSIIIX. S. \& [-1:X7. II. [\%. Habituation to loud vome as a function of manitest anxiety. Journal of tinnormal P!chology. 1970. 75. $189-194$

K.TKI. I . S. K MG L BBI. R. J. Habituation of the crienting reyponse as a function of individual ditforences in anxicty and autonomk lability. Iournal of Abnormal Pycholog! 1469,74, 54-60.

SCHAILLIC, D.. \& LIV'ANDIR. S. Ratings of anxicty-pronenew and responses to electrical pain stimulation. Scandinavian Joumal of Piychology . 1964. 5. 1.8.

SII:GEL. S. Vomparametric statistics. New York: HoGraw-Hill. 1956.

STI IIENS, J. C.. \& TLI IING. E. Estimations of loudness by a group of untrained observers. American Journal of Psychology. 1957. 70. 600-605.

STEVF.NS. S. S. Ratio icales, partition scales and confusion scales. In $H$. Gulliksen and $S$. Messick (F.ds.). Psichological scaling: Theory and applications. New York: Wiles, 1960. Chap. 6.

STEVENS. S. S. To honor 1 echner and repeal his law. Science. 1961, 133,80-86.

SLLLIVAN. R. Subjective matching of anxiety to intensities of white noisc. Journal of Abnormal Psychology, 1969. 74. 646-650.

TAYLOR. J. A personality salc of manifest anxiety. Journal of Abnormal \& Social Psychology. 1953, 48. 285-290.

TORGERSON. W. S. Quantitative judgment scales. In H. Gulliksen and S. Messick IFds.t. Psychological scaling: Theory and applications. New York: Wiley, 1960. Chap. 3. NOTES

1. Sullivan.R., Trupin. F.., \& Blumberg. H. Anxiety, pain and aversiveness: A correlational study. Submitted for publication.

2. In a similar study currently in preparation. the method of successive interval scaling was used to establish category boundaries for different anxiety judgments. As suggested here, the findings indicate that approximately four different anxiety stimuli are present in this experimental setting.

\title{
Age differences in sequential form recognition*
}

\author{
JOAN S. GIRGUSt \\ The City College of the City University of New York, New York, N.Y. 10031 \\ and \\ JULIAN HOCHBERG \\ Columbia University, New York, N.Y. 1002\%
}

Children (ages 3.7 to 9.2 years) viewed patterns moved continuously behind a stationary aperture, identifying the shapes by referring to a confusion matrix. Age affected recognition of sequentially viewed (but not simultaneously viewed) shapes; recognition errors for the different shapes (square, cross, and " $E$ ") were only marginally different.

Adults are able to recognize forms presented sequentially by exposing them in piecemeal fashion through an aperture that is smaller than the whole pattern (Parks, 1965: Anstis \& Atkinson, 1967; Haber \& Nathanson, 1968; Hochberg, 1968). Although sensory factors can account for the integration of the successive views when the latter are presented in rapid succession (Anstis \& Atkinson. 1967),

*This research was supported in part by NSF Grant GB 5270

$\div$ The first author was an $\mathrm{NIH}$ predoctoral fellow at the New School for Social Research at the time this experiment was perfomed. adults also easily recognize forms with slow piecemeal presentation (Hochberg, 1968; Haber \& Nathanson, 1968), thus implying more central integration of the sequentially presented stimuli.

In fact, if a set of comers and sides is presented in a discrete and discontinuous sequence (e.g., a static view of a corner followed by a static view of a side, followed by another corner, etc.), so that the $S$ is given no external information concerning each feature's relative location, only his knowledge of the overall pattern can explain his identification of the series of views when they are longer than his immediate memory span (Hochberg.
1968). That is. only an organizing schematic map would enable the $S$ to recognize such discontinuous successive input as being a part of some specific shape. This kind of sequential piecemeal presentation might therefore provide us with a tool with which to study children's acquisition of such visual concepts or schemas.

We were not at all sure, however, that young children could recognize any forms, even familiar ones, presented in discontinuous piecemeal sequence. A continually moving pattern, viewed through an aperture, presents the $S$ with a less demanding task in the following fashion: If cues to the directions of movement are given, so that the $S$ actually sees each corner and side passing behind the aperture. the stimulus contains definite information about the relative positions of each shape's corners and sides. If there are more features than the $\mathrm{S}$ can retain as isolated elements in immediate memory, however-i.e., if he has no overall schematic map of the shape-he should not be able to recognize the form that is presented in this manner, even though the movement cues are provided (Hochberg, 1968). The present experiment was therefore undertaken using the less demanding method of aperture viewing (i.e., with continuous movement cues given) to see if preliterate children could recognize two familiar forms and one somewhat less familiar form presented in this fashion.

\section{SUBJECTS}

Twelve children between the ages of 3 and 10 years served as Ss. They were divided into three age groups: six 3 - to 4-year-olds (three girls and three boys, mean age 3.7 years), three 5 - to 6 -year-olds (one girl and two boys, mean age 6.0 years), and three 8- to 9-year-olds (three boys, mean age 9.2 years).

\section{APPARATUS}

The stimuli to be recognized were an outline square, cross, and block $E$. The side of the square was equal in length to one arm of the cross and to the middle arm of the block E. Each stimulus was prepared for presentation in two ways: (1) whole form presentation-the form was drawn with a soft pencil on a white index card-and (2) sequential form presentation-each stimulus was drawn on an index card and photographed with a motion-picture camera through a circular aperture cut in a piece of gray construction paper. The diameter of the aperture was equal to the length of one side of the square. The first view of each form was of a corner (right-angle), which subscribed one-quarter of the area of the aperture. Each photographed view, moving 
Table 1

Percent Correct Recognitions of Sequentially Presented Forms Per Age Group and Per Stimulus

\begin{tabular}{|c|c|c|c|c|c|}
\hline $\begin{array}{l}\text { Wean Age } \\
\text { in Ycars } \\
\end{array}$ & $\therefore$ & Square & Cross & Block "l:" & $\begin{array}{c}\text { Uaan } \\
\text { Total } \\
\text { Stimuli }\end{array}$ \\
\hline 3.7 & 6 & $33 c$ & $\sigma^{r}$ & $\mathrm{O}^{\prime}$ & $11^{\prime \prime}$ \\
\hline 6.0 & 3 & $66^{\circ}$ & $33 i$ & $33^{\prime}$ & $44 "$ \\
\hline 9.2 & 3 & 100 & $100 \%$ & $66 \%$ & $89^{\prime}$ \\
\hline $\begin{array}{l}\text { Mean Total } \\
\text { Age Groups }\end{array}$ & 12 & $58 \%$ & $33 \%$ & $25 \%$ & \\
\hline
\end{tabular}

successively around the contour of the form, was one-eighth of the length of one side of the square further along the contour than the view before (see Fig. 1). Two frames per view were shot for the square. one frame per view for each of the other two forms, so as to make the stimuli approximately equal in terms of the total time of passage of the form beneath the aperture. The motion picture of the square lasted about $4 \mathrm{sec}$, of the cross about $4 \frac{1}{2} \mathrm{sec}$, and of the block $E$ about $5 \mathrm{sec}$.

The three stimulus forms plus an outline triangle, an outline diamond, and an outline five-pointed star were drawn on index cards with a soft pencil and then were placed on a table top in two rows (randomly ordered) to serve as the confusion matrix from which $S$ was to make his choices. The proportions of the three forms on which $S$ was tested were the same in the matrix as in the test stimuli: the three nontested stimuli were all equilateral, with each side the same length as one side of the square.

The wholly presented forms (on index cards) and the confusion-matrix forms (also on index cards) consisted of black line drawings on a white background, while the sequential presentation forms (the motion pictures) were white lines on black background because the latter were presented in their negative form. PROCEDURE

Each of the three stimuli was presented once to each $S$ in the two ways described

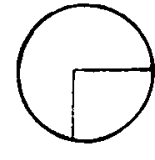

1
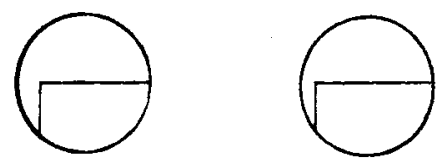

6 above. Each index card with a stimulus on it was shown to $S$ for about $5 \mathrm{sec}$ at a distance of about $2 \mathrm{ft}$. The motion pictures were projected on a blank wall about $4 \mathrm{ft}$ in front of $S$. The size of the diameter of the aperture at this distance equals $1 \mathrm{in}$. The order of presentation always consisted of the whole forms (index cards) randomly ordered, followed by the three sequentially presented forms (movies) randomly ordered. After each presentation of a single stimulus, $\mathrm{S}$ was asked to turn around and choose what he had just seen from the confusion matrix, which was on a table top to his left.

\section{RESULTS}

When the stimuli were presented on index cards (whole presentation), all $\mathrm{Ss}$ at all ages demonstrated $100 \%$ accuracy of recognition. Table 1 presents the percent correct recognitions per age group and per stimulus for the sequential presentation condition (movies).

The total scores (number of correct recognitions) per $S$ were analyzed for differences between age groups by a Kruskal-Wallis one-way analysis of variance $(\mathrm{H}=8.4, \mathrm{df}=2, \mathrm{p}<.02)$. The difference in correct recognitions among the three stimuli were analyzed by a Cochran $Q$ test $(\mathrm{Q}=5.2, \mathrm{df}=2, \mathrm{p}<.10)$.

\section{DISCUSSION}

It is clear that there are definite age differences in the ability to recognize simple geometrical forms when they are presented sequentially. The total traverse

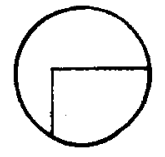

3
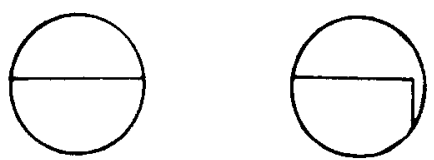

8
Fig. 1. The first eight views of the square in the sequential presentation condition (movies). times of the forms beneath the aperture used in this study were fairly long. Still at issue is the question of whether shorter times of total traverse (say on the order of the 250-500 msec used by Parks. 1965) would improve performance in children. i.e. Would make the temporal integration that much easicr.

Although the differences in correct recognition among the three stimulus figures was only marginally significant, it seems reasonable to expect that the square would be easier to integrate than either the cross or the block $E$ under these circumstances, since it has many fewer corners (Attneave, 1954).

It should be noted that the same patterns that are difficult to recognize when presented sequentially are easily recognized when they are presented to young Ss in their entirety. However, even in this latter case, since the forms were too large to fall entirely on the fovea, the Ss must sample each pattern by a sequence of fixations. This would seem to imply that when Ss are premitted to determine the sequence and rate of presentation of the stimulus components and when they receive diffuse peripheral information, the task is not a difficult one. A rather slow sampling of relatively small sections of the pattern seems to make the task of integrating the information into a single perceptual unit a formidable one for young children. It would therefore be of interest to see if other stimuli for which the presentation of the units of information is necessarily sequential (e.g., animated cartoons involving cutting) would create difficulties of integration comparable to those found in this study.

\section{REFERENCES}

ANSTIS, S. M., \& ATKINSON, J. Distortions in moving figures viewed through a stationary slit. American Journal of Psychology, 1967, $80,572-586$.

ATTNEAVE. F. Some informationai aspects of visual perception. Psychological Review. 1957. 64, 97-103.

BLANK, M., \& BRIDGER, W. Perceptual abilities and conceptual deficiencies in retarded readers. In J. Zubin (Ed.), Psychopathology of intelligence. Transactions of the American Psychopathological Association. Yew York: Grune \& Stratton, 1967. Pp. 401-412.

BLANK, M., WEIDER, S., \& BRIDGER, W. Verbal deficiencies in abstract thinking in early reading retardation. American Joumal of Orthopsychiatry, 1968, 38, 823-834.

HABER, R. N., \& NATHANSON, L. S. Post-retinal storage? Some further observations of Parks' camel as seen through the eye of a needle. Perception \& Psychophysics, 1968, 3, 349-355.

HOCHBERG, J. In the mind's eye- In R. N. Haber (Ed.), Contemporary theory and research in visual perception. New York: Holt, Rinehart, \& Winston, 1968. Pp. 309-331.

PARKS, T. E. Post-retinal visual storage. American Journal of Psychology, 1965, 78. 145-147. 